\title{
Blogging during a Crisis: Threat and Efficacy in Online Communication during a
}

\section{Hurricane}

\section{Toni Siriko Hoang, University of Houston-Downtown, USA}

\begin{abstract}
Analyses of weather blogs reveal topics discussed by bloggers before Hurricane Ike. Messages included all four components (perceived susceptibility, perceived severity, response efficacy, and self-efficacy) of the Extended Parallel Process Model only $13 \%$ of the time. As time approached hurricane landfall, findings suggest bloggers fail to motivate protective behavior, for which threat and efficacy appeals must be present. The threat/efficacy disproportion could have profound effects when one considers the timing of the messages. Overall, perceived severity appeared most frequently in posts, and response efficacy was present more in readers' comments.
\end{abstract}

Keywords: blogging, crisis, communication, efficacy 


\section{Introduction}

Hurricanes are media events, which create a whirlwind of information seeking activity as people search for up-to-the minute news. Traditional news sources serve as a conduit for mass broadcasts of storm updates, safety information, and school and business closures. Email, instant messaging, texting, and social media complement traditional news sources by offering direct and immediate personal communication exchanges. Another means for managing information comes via blogs (web logs). A blog is an online journal where an author filters news and self-publishes information on a website. Blog users are able to read and post comments, questions, photos, videos, and links within a chronological and archival format. Because anyone (media outlets, weather experts, or concerned citizens) can create a blog in the blogosphere, the rapid popularity of blogging is unique for its blend of traditional media and web communication.

Despite the interest in blogging, relatively little is known about the messages that blogs are communicating. Even less is understood about the relationship between blogs and traditional media. At worst, hurricane blogs may undermine reports from weather experts, city officials, and government agencies. At best, hurricane blogs may serve to counterbalance national news reports with first-hand accounts, identify and inform vulnerable communities, and educate the public. This investigation examines the trend of hurricane blogs. A content analysis was used to determine what messages hurricane blogs are communicating to blog users and what, if any, perceptions of credibility blog users may have about other news sources.

\section{Hurricane Risk Communication and Preparedness}

Dissemination of information is a well-known challenge for risk communicators. Failure of complete, accurate, and prompt delivery of communication can compound an already distressing emergency situation. In some cases, warning systems are able to alert attention but are unable to successfully communicate adequate information about the situation. Even the best of systems and the quality of the warnings people receive, however, only partly account for how people may eventually respond. Other matters, such as personal disabilities, previous experience with and knowledge of the hazards, social class, ethnicity, race, and proximity and other available physical clues to the hazard, have important effects on how people define situations in which they find themselves negotiating their actions (Aguirre, 2004). "Crises 
that precipitate a surge in personal communication as well as heightened consumption of mass media sources ranging from radio and TV to news websites and blogs has been described global crisis communication" (Thelwall \& Stuart, 2007, p. 189; see also Bucher, 2002).

Communicating hurricane risk is a dynamic and difficult task. Hurricane Katrina, for example, was every bit a communication disaster as it was a natural disaster. "Communication gaps, missed signals, information technology failures, administrative buffering, turf battles, and deliberate and unintentional misinterpretations delayed and handicapped both the recognition of the crisis that Katrina posed and the response to its devastation" (Garnett \& Kouzmin, 2007, p. 171). A significant weather event, such as a hurricane, generates a high level of public interest and an immediate communication need for information relevant to the hurricane's development, track, potential damage, and safety of loved ones. Various communication channels are necessary to disseminate these types of messages, and communication technologies are important as they increase the opportunity for gaining multi-channel information.

The study of risk perception aims to discover what people understand to be a risk, predict how people might respond to hazards and risk management strategies, and improve the communication of risk messages (Slovic, Fischoff, \& Lichtenstein, 1982; see also Dow \& Cutter, 2000; Lazo, Morss, \& Demuth, 2009). While the body of literature is extensive on information seeking and processing before the onset of a hurricane disaster, few studies present a comprehensive and longitudinal perspective of the practices before, during, and after the event. Since hurricanes are a continuous threat to the United States' coastal communities, effective communication warrants constant attention.

Blogging When in Crisis

Thus far, there have been no limits to the explosion of blogging activity. Experts and lay people blog about personal, social, and political issues. Thelwall and Stuart (2007) compared blogging communication technologies during three major crises in 2005: the suicide bombing attacks on London's public transportation system, Hurricane Katrina, and the PakistanKashmir earthquake. The researchers concluded that bloggers relied on a variety of communication technologies, including national and regional mass media and personal 
communication (Thelwall \& Stuart, 2007). The same study also reveals that bloggers prefer different communication technologies depending on the crisis. For instance, during Hurricane Katrina, local news media was a significant information source for bloggers; however, this was not the case for the London attacks, during which bloggers relied on Wikipedia and Wiki news. The findings do not suggest a preferred communication technology for bloggers writing about the Pakistan-Kashmir earthquake. Thelwall and Stuart's (2007) work not only highlight information sources for bloggers, but it was able to capture the increase in blogging activity during a crisis by employing processing software to monitor blogs and extract frequently used crisis-related words.

Blogs even play a role during an organizational crisis. Sweetser and Metzgar (2007) analyzed individuals' perceptions of an actual crisis. Participants were assigned to either read a personal blog of the event, the organization's blog of the event, or placed in a control group. The findings indicate that people who read the blogs (personal or organizational) perceived a lower level of a crisis for the organization than those who were not exposed to a blog, and those exposed to the organizational blog reported the lowest score for the crisis among the groups (Sweetser \& Metzgar, 2007). The implications of the findings suggest that the type of blog may have an influence on people's perceptions of the magnitude of a crisis; thus, "they may have great promise as an organizational crisis management tool" (Sweetser \& Metzgar, 2007, p. 342). Moreover, the study provides clues as to people's perceptions of credibility of blogs.

Publics have long relied on different information sources (i.e. local news, national news, scientific experts, social networks, or neighbors) during hurricane events. The findings of Thelwall and Stuart (2007) as well as Sweetser and Metzgar (2007) emphasize that individuals' beliefs during a crisis are not only influenced by the communication channel (e.g. blogs) by which a message travels but also the executor of the message. Lindell, Lu, and Prater (2005) surveyed risk area residents about hurricane evacuations in response to Hurricane Lili, which traveled toward the central Texas coast before ultimately making landfall on the south central coast of Louisiana in 2005. The researchers found that residents reported they relied most on local media as opposed to national media and more on local authorities than peers. In addition, those residents closer to the coast, rivers, or lakes, were more likely to rely on local authorities. 
Theorizing Risk

One of the strongest motivators for attitude and behavioral change is the sense of fear. Fear is defined as "an internal emotional reaction composed of psychological and physiological dimensions that may be aroused when a serious and personally relevant threat is perceived" (Witte, Meyer, \& Martell, 2001, p. 20). Studies of risk have frequently focused on the perception of fear as a key factor in motivating one's behavior. Janis (1967) argues that fear arousal is the most effective means of persuasive communication and suggests that some fear is necessary for successful persuasive messages, while too little fear does not arouse any reaction. Research suggests awareness of personal risks was heightened when people viewed graphic images of automobile crashes and mortuaries (Sutton \& Hallett, 1989) and pictures of the effects of cigarette smoking to the body (Sutton \& Hallett, 1988). Since people are more likely to remember pictures than words (see Nelson, 1979; Paivio \& Csapo, 1973), which can induce an emotional response (Pfau, Haigh, Fifrick et al., 2006), memories of other hurricanes and the magnitude of the destruction they caused can increase their motivation to prepare for such an event.

\section{Extended Parallel Processing Model}

Assessing our exposure to risk creates a compelling desire for understanding the cognitive processes that occur when a threat is present. People are motivated to perform protective behaviors when they fear a significant threat and when they perceive a response that would avert the threat (Witte, 1992). In contrast to the reduction of fear, in which people attempt to avoid an emotional state of fear, the extended parallel processing model (EPPM) draws from the previous frameworks by offering justifications to fear control processes (Kim, 2004), whereas others focused on danger control processes (Leventhal, 1970).

The EPPM's applicability has been demonstrated in a significant breadth of health topics, including safer sex practices (see Cho \& Witte, 2005) and smoking cessation (see Wright, French, Weinman, \& Marteau, 2006). In one study, Gore and Bracken (2005) asked individuals to report their responses about meningitis vaccinations. The study focused on college students as previous research noted college students living in on-campus dormitories may be more susceptible to the virus. The EPPM successfully predicted that a highefficacy/no-threat health message persuaded individuals from fear control to move toward 
danger control, and a high-threat/no-efficacy health message persuaded individuals from fear control to higher fear control processes regarding meningitis vaccinations. The study also found that exposure to a high-threat/no-efficacy health message persuaded individuals from danger control to fear control processes. These findings underscore the EPPM's key propositions of the relationship between threat and efficacy. "The critical point occurs when perceptions of threat begin to outweigh perceptions of efficacy, causing individuals to shift from danger control responses to fear control responses" (Gore \& Bracken, 2005, p. 37; see also Witte, 1992).

The EPPM also helped LaVela, Smith, \& Weaver (2007) to assess whether danger or fear control processes are dominating in veterans' responses to an influenza threat. The findings suggest that most veterans perceived efficacy to be stronger than the threat of the virus. That is, the individuals are more likely to engage in a danger control response (e.g. receive an influenza vaccination). However, this did not significantly differ from the control group. One explanation given was the variety of health campaigns to increase influenza vaccinations, which have been ongoing for a number of years, may be responsible for an overall high rate of compliance to vaccination recommendations. Similar to past research, LaVela et al. (2007) express that health campaigns must contain appropriate efficacy messages, in addition to threat messages, in order to promote behavioral change.

The strength of the EPPM has allowed researchers to apply the model in efforts to prevent the risk of occupational and safety hazards as well. Murray-Johnson, Witte, Patel, Orrego, Zuckerman, Maxfield, and Thimons (2004) evaluated the EPPM dimensions in addition to subjective norms and channel preferences of coal miners' regarding hearing loss and hearing protection. Among the findings, it was not surprising that all participants agreed hearing loss was harmful, serious, and affecting quality of life. Self-efficacy, however, was weaker than response efficacy due to comfort, hygiene, and cost concerns. Murray-Johnson et al. (2004) also reveal that fear appeals and "nagging" from family members and spouses to prevent hearing loss is not effective. Many miners used humor and joked that they were not "a bunch of scared men" (Murray-Johnson et al., 2004, p. 750). Witte, Peterson, Vallabhan, Stephenson, Plugge, Givens, et al. (1993), also report unexpected perceptions of preventing tractor-related injuries and deaths. While tractor operators recognize the severity of farm equipment accidents, they do not particularly feel vulnerable. Witte et al. (1993) advocate for 
subsequent safety messages to target fear control processes, which will increase one's susceptibility and perceived efficacy, in order to challenge the operators' lax attitude towards exposure to tractor safety risks.

In another study, attendees of hunter safety classes were exposed to a video-based intervention about gun safety practices. The EPPM suggests that individuals recognize a level of threat, which is created by perceived susceptibility and severity to a risk. Furthermore, if strong enough, the level of threat should motivate individuals to take action which assumes a high level of efficacy (Roberto, Meyer, Johnson, \& Atkin, 2000). Thus, Roberto et al. (2000) hypothesized that individuals who watched the gun safety video would (1) recall significantly more recommended gun safety practices, (2) perceive their susceptibility to gun injuries as being significantly greater, (3) perceive gun injuries as significantly more severe, and (4) perceive significantly more response efficacy than individuals who were in the control group. After conducting a survey of 175 hunter safety class attendees, the findings were significant for hypotheses 1-3, where the experimental group reported more of the six recommended gun safety practices, they were more likely to believe that they or their gun might be involved in an accidental shooting, and they were more likely to believe that gun injuries result in greater suffering. The finding for hypothesis four, that individuals felt each gun safety practice was effective in preventing injuries, was in the direction predicted; however, it did not reach significance. While the investigation provides clues of individuals' fear control responses, actual behavior change can only be presumed. Notwithstanding this, "the evidence suggests that the strong intention - behavior relationship is generalizable to gun safety" (Roberto et al., 2000, p. 171).

The EPPM has even been extended to explore the perception of risk messages to an unknown risk. McMahan, Witte, and Meyer (2009) examined perceptions of risk related to electromagnetic fields (EMFs) and observed the effectiveness of different risk messages (low vs. high threat) in motivating adaptive response behaviors. Participants in the study received either a low-threat or high-threat risk message about EMFs which was followed by a questionnaire. "Consistent with the EPPM predictions, threat motivated stronger or weaker attitudes, but efficacy determined whether the attitudes were positive or negative" (McMahan et al., 2009, p. 254-255). Those with high-efficacy perceptions and who received high-threat messages had the strongest attitudes toward EMF control processes. With regard to intentions, the pattern was also consistent in that high-threat/high-efficacy had the strongest 
intentions to engage in safety behaviors. Low efficacy group, regardless of threat level, reported the weakest intentions. In addition, low-efficacy groups also reported weaker safety behaviors, most likely to engage in defensive avoidance, higher levels of message minimization (denial of the importance of the EMF risk messages), and stronger perceptions of perceived manipulation (reactance against EMF risk messages). The authors conclude that "when messages promote high perceived threat or fear at the expense of increases in response or self-efficacy, they run the risk of producing maladaptive fear-control outcomes," (McMahan et al., 2009, p. 258). This is consistent in other research in which "the EPPM suggests that when the efficacy level exceeds the threat level, an individual should express an intent to enact the recommended behavior(s), but when the threat level exceeds the efficacy level, an individual will express denial or avoidance,” Roberto et al. (2000, p. 170).

As the previous sections demonstrate, the EPPM is a strong theoretical framework for understanding hurricane risk. Building on protection motivation theory (Rogers, 1975, 1983), the EPPM emphasizes the process of cognition. That is, rather than reflexive responses to instinctive events, engaging in a deliberate behavior to manage one's fear involves a sustained process. Second, the EPPM underscores that one is coping with an event rather than escaping from an unpleasant emotional state. The model focuses on an individual's perceived self-efficacy - do I believe I have some control over hurricane risks; response efficacy - how can I reduce the risk of a hurricane; susceptibility - how vulnerable am I to hurricanes; and severity - to what extent could I be affected by hurricanes. Thus, Research Questions 1-3 ask:

RQ1: What percentage of hurricane blog posts contains all four components of the EPPM (perceived susceptibility, perceived severity, response efficacy, and self-efficacy)?

RQ2: What percentage of hurricane blog posts is missing one or more threat component (perceived susceptibility and perceived severity)?

RQ3: What percentage of hurricane blog posts is missing one or more efficacy component (response efficacy and self-efficacy)?

Choi and Lin (2008) used the EPPM to analyze newspaper coverage of three major hurricanes in 2005 during a one-week period before the storms actually occurred. Researchers were able to create categories based on the four EPPM message components of response efficacy ("actions to take to prevent risk"), self-efficacy ("expected outcomes of 
taking actions"), susceptibility ("anticipated outcomes"), and severity ("the intensity of the hurricane"). The researchers report the most frequent type of message was "actions to take to prevent the risk" ( $n=936$ or 62\%), followed by "anticipated damages" ( $n=286$ or 19\%), "the intensity of the hurricane" ( $n=282$ or 19\%), and "expected outcomes of taking actions" ( $n=3$ or $0.02 \%$ ). Moreover, Choi and Lin (2008) found stories emphasized preventative actions with appeals such as "Take the storm seriously," Follow directions," and "Remain calm." Another interesting finding is that the study reveals that newspapers rarely mention what are the expected outcomes of the recommended actions. As supported by previous research (see LaVela et al., 2007), stating the expected outcomes of a recommended preventative action (prompting self- and response efficacy) was noted as being an integral criterion for performing the action. News coverage relied heavily on delivering key hurricane risk information; thus, heightening the public's emotional response to fear. Choi and Lin (2008) add that emotional frames may help people better understand a potential risk. This notion is supported by Lerner \& Keltner, 2001, who claim appraisal tendencies mediate the causal effects of fear upon optimism. The current study aims to partially replicate Choi and Lin's (2008) work by applying the same EPPM derived categories to evaluate blogs by hypothesizing:

H1: Overall, hurricane blog posts will most frequently convey messages associated with actions to take to prevent risk (response efficacy).

Finally, the EPPM can be applied to forms of managing risk where no fear is aroused (e.g. pre- or post-hurricane season) yet one engages in protective activity (e.g. preparing a household emergency kit). Past research has demonstrated the change in news media involvement during a hurricane event; yet, less is known regarding the fear control and danger control processes rooted in the messages. In their investigation, Barnes, Hanson, Novilla, Meacham, McIntyre, and Erickson (2008) found the focus of national and local newspaper coverage of Hurricane Katrina changed dramatically before, during and after the hurricane. On average, newspapers published 2.5 articles per day before the storm hit, twenty-eight articles during the storm, and fifty-eight articles after the hurricane made landfall. Significant differences were found among articles, which focused on public health disaster management practices for preparation, mitigation, response, and recovery during prehurricane, hurricane on land, and post-hurricane times (Barnes et al, 2008). Given the topical shift in newspaper coverage, it may be reasonable to assume that hurricane blogs may follow 
a similar pattern. To advance the findings of Barnes et al. (2008), the current study proposes to understand fear control and danger control processes by examining how perceptions of threat and risk in hurricane blog messages may change over time. Thus, Research Question 4 asks:

RQ4: Is there a difference in percentages of the EPPM components in hurricane blog posts as time approaches hurricane landfall?

\section{Method}

\section{Definitions}

For the purpose of this study, a blog is an interactive website which a blogger displays messages about a particular topic - usually in reverse chronicle order - and to which online users can view and respond to such messages. The blogger's messages are called posts, whereas the readers' responses are referred to as comments.

\section{Sampling Procedure}

The researcher performed a content analysis on national and local weather blogs about Hurricane Ike. EPPM components for each weather blog were examined. Posts were analyzed for blogger and user activity (i.e. providing links, quotes, pictures, etc.) and message content (i.e. perceived susceptibility, perceived severity, response efficacy, and self-efficacy).

Blog sites active during the three days preceding Hurricane Ike's landfall were included in the sample. The official report, issued by the National Hurricane Center, indicated the storm's landfall was September 13, 2008. Three to seven days prior to hurricane land fall has been used as an acceptable period during which much communication is generated about active hurricanes (see Choi \& Lin, 2008; Wenger \& Friedman, 1986). Thus, the sampling time frame begins 12:01AM, September 10, 2008 and ends on 11:59PM, September 12, 2008.

\section{Blog Site Identification and Selection}

The analysis focuses on the most popular and recognized weather-related blogs. This is determined by a cross check of science blogs that were recognized during the 2008 Weblog Awards for "Best Science Blog" and the "Top 10 Weather and Climate Blogs" list featured on Blogs.com. One blog, Real Climate, appeared on both lists. This yielded nineteen blog sites. The "Top 10 Weather and Climate Blogs" is contributed by Doyle Rice of USA Today and blogger of The Weather Guys; therefore, the decision was made to include The Weather 
Guys blog. In all, twenty national blogs were identified. From the twenty blog sites, nine of them were excluded for one or more reasons including: no available archive or no hurricanespecific content for the sample time frame, even when the blog was active. This resulted in a sample $(n=11)$ of national blogs: 60-Second Science, Capital Weather Gang, Dot Earth, Greg Laden, Jeff Master's WunderBlog, Meteorological Madness, NASA Watch, Philly Weather.net, WeatherBug Backyard Club, Weather.com Blog, and WGN Weather Blog. W Weather blogs featured on the websites of local news media (television and newspaper) serving the Houston-Galveston region were identified. Blogs were carefully examined for hurricane-specific content within the sample time frame, as exercised during the national blog identification process. Local weather blogs $(n=4)$ in the analysis include: 11 Weather Blog (CBS affiliate, KHOU), Weatherblog.abc13 (ABC affiliate, KTRK), Sci Guy (The Houston Chronicle), and Weather Watch (The Galveston County Daily News). In total, fifteen ( $n=$ 15) national and local weather blogs are represented in the sample.

\section{Blog Post Selection}

The unit of analysis is each individual post appearing in the fifteen blog sites and within the sampling time frame. Posts $(n=105)$ were included in the analysis if they (1) are specific to Hurricane Ike, and (2) fall within the three days prior to the hurricane's landfall as reported by the National Hurricane Center (September 13, 2008). Thus, the three days prior to hurricane landfall are represented by Time 1 (September 10, 2008), Time 2 (September 11, 2008), and Time 3 (September 12, 2008). In addition, the analysis focused only on the text of the posts. The content of any videos, pictures, graphics, or links provided within a post were not analyzed.

\section{Coding and Scale Development}

A codebook was created to identify messages in blogs based on the four components of the EPPM (Witte, 1992): perceived susceptibility, perceived severity, response efficacy, and selfefficacy. The EPPM, as well as definitions and examples of its components, are found in Appendix A and B, respectively.

Threat and Efficacy

To satisfy the research questions and hypothesis, message content was coded based on previous research (see Choi \& Lin, 2008) using four topic categories derived from the EPPM 
(Witte, 1992). Blog messages related to perceived susceptibility or perceived severity fall under the realm of fear control processes and signify threat components. These consist of the categories, "anticipated outcomes or damages" and "the intensity of the hurricane." Examples of messages, which reflect these categories include, "The category five hurricane will cause catastrophic building failures" (perceived susceptibility) and "The hurricane will produce a storm surge over eighteen feet, and wind speeds in excess of 155 miles per hour" (perceived severity). Blog messages related to response efficacy and self-efficacy elicit danger control processes and signify efficacy components. These consist of the categories, "actions to take to prevent risks" and "expected outcomes of taking preventive actions." Examples of messages, which reflect these categories include, "Residents are advised to remove furniture, plants, and loose objects from outdoor spaces" (response efficacy) and "By staying away from windows and exterior walls you will be safer" (self-efficacy).

Inter-coder Reliability

The present study employed two coders, which included the researcher and an undergraduate student assistant. The assistant was first introduced to the research topic and given a general overview of the data collection procedures. Next, the assistant was trained in the theoretical concepts of the EPPM and coding procedures. A session was also conducted by the researcher, where coders visited blogs sites, unrelated to the present study, to explore blog features. Training materials were then provided to the assistant, of which included detailed explanations of the scales and norming examples. Data generated from blog sites outside of the study's sample were used for practice sets. A subsequent meeting occurred the following week where the coders discussed disagreements in their ratings until a mutual understanding was met.

After completion of the practice sets, the coders independent coded approximately $10 \%(n=$ 95) of the final sample. Cohen's $\kappa$ (Cohen, 1960) was used to test the validity of the coding scheme. Reliability for each variable ranged from .34 to .49 . Coders discussed disagreements of the variables. A second training session was conducted to review changes in the codebook and coding worksheets, which were made for clarity and to remove redundant items. Coders independently coded a second subsample, and a second inter-coder reliability test using Cohen's $\kappa$ was performed. This time, reliability ranged from .62 to .80 . Acceptable reliability figures in the .80 and .90 range are most desirable; however, Rifee, Lacy, and Fico (1998) 
argue content research "that is breaking new ground with concepts that are rich in analytical value may go forward with reliability levels somewhat below that range" (p. 131). The ratings were retained based on their relevance to the study.

\section{Data Analysis}

The study used multiple tests to analyze the data. To answer the research questions and hypothesis, frequencies were generated to describe the presence or absence of the EPPM message components (perceived susceptibility, perceived severity, response efficacy, and self-efficacy) in blog posts. Next, chi-square tests were performed to determine whether there were significant differences of the EPPM components and the time at which blog posts occur for Research Question 4. Statistical significance was set at $p<.05$. All tests were performed using SPSS Statistics 17.0.

\section{Results}

This investigation featured a content analysis of national and local weather blogs about Hurricane Ike. Specifically, the analysis aims to describe the content of the blogs' posts in terms of the message components of the EPPM including perceived susceptibility, perceived severity, response efficacy, and self-efficacy. In addition, differences between threat/efficacy messages and the time at which blog messages are posted were examined. Finally, credibility of national and local weather blogs about Hurricane Ike were assessed.

\section{Research Question 1}

The first research question asked what percentage of hurricane blog posts contains all four components of the EPPM (perceived susceptibility, perceived severity, response efficacy, and self-efficacy). Table 1 illustrates frequencies of each EPPM component found overall in blog posts. Only $13 \%$ of the blog posts $(n=14)$ included both threat and efficacy messages. This was observed in blog posts at each time, as well as in both local and national blogs. 
Table 1: Blog Posts and EPPM Components

\begin{tabular}{lllll}
\hline & Overall & Time 1 & Time 2 & Time 3 \\
\hline Containing & $13 \%$ & $21 \%$ & $14 \%$ & $8 \%$ \\
All Four $\quad(n=14)$ & $(n=6)$ & $(n=4)$ & $(n=4)$ \\
EPPM & & & & \\
Components & & & & \\
Missing & $10 \%$ & $7 \%$ & $7 \%$ & $13 \%$ \\
All Four & $(n=10)$ & $(n=2)$ & $(n=2)$ & $(n=6)$ \\
EPPM & & & & \\
Components & & & & \\
\hline
\end{tabular}

When analyzed according to when the blog messages were posted-Time 1 (September 10, 2008), Time 2 (September 11, 2008) and Time 3 (September 12, 2008) - the percentage of blog posts that included all four EPPM components was similarly low across groups (see Table 1). Among blog posts from Time 1, 21\% contained all four components; however, as blog posts approached the date of hurricane landfall fewer posts $(14 \%)$ contained all four components as seen at Time 2 . Finally, the day before hurricane landfall, Time 3 , only $8 \%$ of blog posts contained all four EPPM message components.

The analysis also revealed a number of cases $(n=10$, or $10 \%)$ in which blog posts were missing all four message components (see Table 1). Interestingly, the percentage of posts missing all components remained the same at Time 1 and Time 2 (7\%); yet, nearly doubled at Time 3. Clear examples of when this occurred were when blog posts contained a link, video clip, or graphic but no text. Since the analysis evaluated message content, an absence of all EPPM components was subsequently reported. Occasionally, a blog post containing content was also found to be missing all EPPM components such as when the content used Hurricane Ike as a focal point for climate-hurricane debate. Although there were posts, which refer to Hurricane Ike, they were found to be missing all four EPPM components because there was no specific mention of the intensity of the hurricane (perceived severity), anticipated 
outcomes or damages (perceived susceptibility), actions to take to prevent risks (response efficacy) or expected outcomes of taking preventative actions (self-efficacy).

Table 2: Presence/Absence of the EPPM Components in Blog Posts

\begin{tabular}{|c|c|c|}
\hline & Frequency & Percent \\
\hline \multicolumn{3}{|c|}{ Perceived Susceptibility } \\
\hline Yes & 79 & 75.2 \\
\hline No & 26 & 24.8 \\
\hline Total & 105 & 100 \\
\hline \multicolumn{3}{|c|}{ Perceived Severity } \\
\hline Yes & 86 & 81.9 \\
\hline No & 19 & 18.1 \\
\hline Total & 105 & 100 \\
\hline \multicolumn{3}{|c|}{ Response Efficacy } \\
\hline Yes & 46 & 43.8 \\
\hline No & 59 & 56.2 \\
\hline Total & 105 & 100 \\
\hline \multicolumn{3}{|l|}{ Self-Efficacy } \\
\hline Yes & 15 & 14.3 \\
\hline No & 90 & 85.7 \\
\hline Total & 105 & 100 \\
\hline
\end{tabular}

\section{Research Question 2}

The second research question asked what percentage of hurricane blog posts is missing one or more threat component (perceived susceptibility and perceived severity). As seen in Table 3, $16 \%$ of the overall blog posts were missing only one threat component (either perceived susceptibility or perceived severity). The frequency of missing both threat components was 
$11 \%$ of the total blog posts. A closer analysis reveals the blog posts were missing perceived susceptibility and perceived severity messages $25 \%$ and $18 \%$ of the time, respectively.

According to time, blog posts appear to lack only one threat component more often, rather than both threat components. Also, at Time 1 and Time 2, blog posts were missing perceived susceptibility messages more often than perceived severity messages; although, this was not the case at Time 3 when more blog posts appeared to include these messages more.

Table 3: Absence of Threat Messages in Blog Posts

\begin{tabular}{|c|c|c|c|c|c|}
\hline & Overall & Time 1 & Time 2 & Time 3 & $\chi^{2}$ \\
\hline $\begin{array}{l}\text { Missing only } \\
\text { one threat } \\
\text { component }\end{array}$ & $\begin{array}{l}16 \% \\
(n=17)\end{array}$ & $\begin{array}{l}11 \% \\
(n=3)\end{array}$ & $\begin{array}{l}24 \% \\
(n=7)\end{array}$ & $\begin{array}{l}15 \% \\
(n=7)\end{array}$ & \\
\hline $\begin{array}{l}\text { Missing both } \\
\text { threat } \\
\text { components }\end{array}$ & $\begin{array}{l}11 \% \\
(n=12)\end{array}$ & $\begin{array}{l}11 \% \\
(n=3)\end{array}$ & $\begin{array}{l}10 \% \\
(n=3)\end{array}$ & $\begin{array}{l}13 \% \\
(n=6)\end{array}$ & \\
\hline $\begin{array}{l}\text { Missing } \\
\text { Perceived } \\
\text { Susceptibility }\end{array}$ & $\begin{array}{l}25 \% \\
(n=26)\end{array}$ & $\begin{array}{l}21 \% \\
(n=6)\end{array}$ & $\begin{array}{l}24 \% \\
(n=7)\end{array}$ & $\begin{array}{l}19 \% \\
(n=13)\end{array}$ & $.312, p=.856$ \\
\hline $\begin{array}{l}\text { Missing } \\
\text { Perceived } \\
\text { Severity }\end{array}$ & $\begin{array}{l}18 \% \\
(n=19)\end{array}$ & $\begin{array}{l}11 \% \\
(n=3)\end{array}$ & $\begin{array}{l}21 \% \\
(n=6)\end{array}$ & $\begin{array}{l}21 \% \\
(n=10)\end{array}$ & $1.404, p=.496$ \\
\hline
\end{tabular}

\section{Research Question 3}

The third research question asked what percentage of hurricane blog posts is missing one or more efficacy component (response efficacy and self-efficacy). Table 4 illustrates blogs posts, which are missing efficacy messages. Overall, 30\% of the all blog posts were missing only one efficacy component (either response efficacy or self-efficacy). The frequency of 
missing both efficacy components was $56 \%$ of the total blog posts. A closer analysis reveals the blog posts were missing response efficacy and self-efficacy messages $56 \%$ and $86 \%$ of the time, respectively. According to time, blog posts appear to lack both efficacy components more frequently, rather than only one efficacy component. In fact, as time progressed from Time $1(43 \%)$, Time $2(52 \%)$, and Time $3(67 \%)$, there was an increase in missing both efficacy components in blog posts. More specifically, blog posts missing response efficacy increased across the groups over time $(43 \%, 52 \%$, and $67 \%$, respectively). The trend continued for missing self-efficacy messages at Time 1 (79\%), Time 2 (83\%), and Time 3 $(92 \%)$.

Table 4: Absence of Efficacy Messages in Blog Posts

\begin{tabular}{|c|c|c|c|c|c|}
\hline & Overall & Time 1 & Time 2 & Time 3 & $\chi^{2}$ \\
\hline $\begin{array}{l}\text { Missing only } \\
\text { one efficacy } \\
\text { component }\end{array}$ & $\begin{array}{l}30 \% \\
(n=31)\end{array}$ & $\begin{array}{l}36 \% \\
(n=10)\end{array}$ & $\begin{array}{l}31 \% \\
(n=9)\end{array}$ & $\begin{array}{l}25 \% \\
(n=12)\end{array}$ & \\
\hline $\begin{array}{l}\text { Missing both } \\
\text { efficacy } \\
\text { components }\end{array}$ & $\begin{array}{l}56 \% \\
(n=59)\end{array}$ & $\begin{array}{l}43 \% \\
(n=12)\end{array}$ & $\begin{array}{l}52 \% \\
(n=15)\end{array}$ & $\begin{array}{l}67 \% \\
(n=32)\end{array}$ & \\
\hline $\begin{array}{l}\text { Missing } \\
\text { Response } \\
\text { Efficacy }\end{array}$ & $\begin{array}{l}56 \% \\
(n=59)\end{array}$ & $\begin{array}{l}43 \% \\
(n=12)\end{array}$ & $\begin{array}{l}52 \% \\
(n=15)\end{array}$ & $\begin{array}{l}67 \% \\
(n=32)\end{array}$ & $4.397, p=.111$ \\
\hline $\begin{array}{l}\text { Missing } \\
\text { Self-Efficacy }\end{array}$ & $\begin{array}{l}86 \% \\
(n=90)\end{array}$ & $\begin{array}{l}79 \% \\
(n=22)\end{array}$ & $\begin{array}{l}83 \% \\
(n=24)\end{array}$ & $\begin{array}{l}92 \% \\
(n=44)\end{array}$ & $2.762, p=.251$ \\
\hline
\end{tabular}

\section{Hypothesis One}

Hypothesis one stated that hurricane blogs will most frequently convey messages associated with actions to take to prevent risk (response efficacy). The hypothesis was not supported. Frequencies illustrated in Table 2 reveal that blog posts communicated messages associated 
with the severity of the hurricane (perceived severity) most frequently, or $82 \%$ of the time; followed by messages associated with anticipated outcomes or damages (perceived susceptibility) which appeared in blog posts $75 \%$ of the time, messages associated with actions to prevent risks (response efficacy) appeared in blog posts $44 \%$ of the time, and messages associated with expected outcomes of taking preventative actions (self-efficacy), which appeared only $14 \%$ of the time.

\section{Research Question 4}

The fourth research question asked whether there is a difference in percentages of the EPPM components in hurricane blog posts as time approaches hurricane landfall. Tables 3 and 4 (see last column) illustrate the results of chi-square tests of the EPPM components across all groups. To understand how perceived susceptibility, perceived severity, response efficacy and self-efficacy independently operated, Pearson's chi-square $\left(\chi^{2}\right)$ statistic was calculated for each EPPM component to determine if there were significant differences between Time 1, Time 2, and Time 3. The results indicate that there is no statistically significant difference between time and perceived susceptibility $\left(\chi^{2}(2)=.312, p=.856\right)$, perceived severity $\left(\chi^{2}(2)\right.$ $=1.404, p=.496)$, response efficacy $\left(\chi^{2}(2)=4.397, p=.111\right)$, or self-efficacy $\left(\chi^{2}(2)=\right.$ $2.762, p=.251)$.

\section{Discussion}

The purpose of this investigation was to apply the EPPM to weather blogs about Hurricane Ike to determine whether the posts contain messages to stimulate threat and efficacy appraisals. Past scholars assert "interactive communication has a promising future" (Taylor \& Perry, 2005, p. 216); yet they fall short of studying a specific modality, such as blogging. Studies have also attempted to evaluate the use of the internet at various times during crisis, but the findings provide little evidence related to a specific event and do not include the perspective of the audience (see Perry, Taylor, \& Doerfel, 2003). Herring et al. (2005) describe blogging as the "bridging genre" (p. 143) for its potential to be interlinked, interactive, and oriented towards external events. Whether blogs reflect forms of selfexpression or collectivistic views, they represent a breadth of issues about health, politics, celebrity gossip, and a host of other categories. 
This study accomplished two broad goals. First, it answered the call to focus interactive communication. Second, the study explored blogging during a specific event (Hurricane Ike) and looked at the frequencies and differences of threat and efficacy messages at various times of the crisis. The results of the content analysis of weather blogs indicate that the significant portion of the posts are likely failing to motivate behaviors to circumvent or reduce the effects of hurricane risks. They simply do not contain the threat and efficacy components. Only $13 \%$ of the weather blogs contain all four EPPM components. Equally concerning, the results indicate a steady decline of the four components as time approaches hurricane landfall (from $21 \%$ to $8 \%$ ) - despite that the number of blog posts increase over time. Witte (1992) argues, "Cognitions about threat and efficacy cause attitude, intention, or behavior changes (i.e. adaptive responses)" (p. 340). The lack of both threat and efficacy appeals in the days prior to hurricane landfall is a missed opportunity for bloggers. This is a critical point when individuals will decide whether response and self-efficacy are still manageable. Not only does the number of blogs containing all four EPPM components decline, but the number of blogs missing the four components rises (from $7 \%$ to $13 \%$ ). If fewer posts contain all message components, it may influence the likelihood that readers engage in maladaptive responses, such as denying the threat of the hurricane, rejecting the hurricane message in the post, or reacting against the message or even the blogger.

The results also show that the most frequently conveyed message component in the blogs was perceived severity followed by perceived susceptibility; thus, the hypothesis was not supported. This contrasts Choi \& Lin's (2008) investigation of newspaper coverage of three major hurricanes, who found response efficacy (actions to take to prevent risk) to be most predominate. Moreover, the researchers did not find either of the threat components as prevalent. The implications of the current findings on hurricane risk information seeking can be significant. Given that the blogs in the current study communicate threat more frequently than not, as well as more often than both efficacy components, jeopardizes the efforts of the blog post if the threat is not accompanied by an efficacy appeal.

When blog posts were missing threat (perceived susceptibility and perceived severity), 11\% of the posts were missing both threat components while $16 \%$ were missing only one. "The EPPM proposes that threat initiates and motivates message processing" (Witte, 1992, p. 339). Essentially, if weather blogs about Hurricane Ike are missing one or more threat component, 
readers may lack a sufficient level of threat and are therefore unlikely to evaluate efficacy components. The findings suggest that readers may not reach the efficacy appraisal process because the blog post was missing one or both threat components, but these percentages may be misleading. The EPPM also proposes that if weather blogs do not contain threat components, but the reader detects threat, the reader may continue with the evaluation of efficacy components. The frequencies represent the content of the written text of each post. It does not fully reflect the threat content, which may be contained in video clips, pictorials, hyperlinks, or sidebar features which were outside the scope of the study. Notwithstanding this, when blog posts do not communicate the anticipated outcomes or damages or the intensity of the hurricane, the audience may be less likely to perform adaptive behaviors including buying supplies, securing loose outdoor items, or evacuating.

The EPPM suggests that if blog posts do contain efficacy components, and the reader perceives a sufficient level of efficacy, then the reader is more likely to comply with the recommended behavior. When blog posts were missing efficacy (response efficacy and selfefficacy), $56 \%$ of the posts were missing both efficacy components while $30 \%$ were missing only one. A closer look reveals posts which were missing response efficacy climbed over time. Most alarming, was that the posts were missing self-efficacy $86 \%$ overall. As time progressed towards hurricane landfall, self-efficacy was missing in blog posts at an increasing rate - as high as $92 \%$ at Time 3 . Witte (1992) argues that missing even one of the efficacy components, the reader may be left with the perception of threat, as well as the feeling that nothing can be done to resolve it. These absences in efficacy exacerbate a dire state for which threat has already been detected.

Chi-square tests revealed the key times for missing EPPM components in blog posts, such as the one, two, or three days prior to hurricane landfall. Although no significant differences were found across the three times for blog posts, the trends support the notion that as time approaches hurricane landfall the perceptions of susceptibility and severity of the threat increases; thus, blog posts may be more likely to include threat messages over efficacy messages. 


\section{Limitations and Future Directions}

Despite the partial confirmation of the EPPM, there were various limitations in this study. One concern focuses on the limitations of the chi-square data analyses. When assessing the EPPM message content for blog posts, the data did not meet the assumptions for the analysis (that the observations must be independent). This error was realized after the data had been collected, coded, and entered into SPSS. Removing repeated measures would have resulted in a significant loss of data. Future investigations should ensure appropriate coding procedures to prevent the loss of explanatory power in the findings. Nonparametric statistical procedures, such as logistic regression, could be a possible solution for future analysis; however, this would require coding the data according to blogger or blog reader.

In addition, the expected cell size for some chi-square tests was violated with fewer than five cases. This, however, did not impact the results of the tests as they were found to be nonsignificant. One remedy in future studies may be to calculate Fisher's exact test to confirm significance. Fisher's exact test has been more accurate than the chi-square when the values are small. Even so, there is some support that chi-square tests can be remarkably robust under these conditions (see Roscoe \& Byars, 1971).

A second limitation involves the role of faith as response efficacy. During data analysis, it was discovered that one of coders viewed expressions of faith as a response to avert a threat; thus coding messages as containing response efficacy. This poses an interesting question for researchers to consider prayer or well-wishing as response efficacy. Moreover, future studies should closely examine whether various types of responses (e.g. prayer, evacuation, buying supplies) influence each other or self-efficacy for that matter. It may also be important to know whether one or more types of responses supersede others. That is, an individual may believe prayer is the more effective response the day before hurricane landfall, in lieu of evacuation or buying supplies. From a broader perspective, many may view blogging about any topic as low on the list of priorities when it comes to hurricane preparedness.

Third, whether blog readers were individuals who expected to be directly or indirectly affected by Hurricane Ike may have influenced the outcome of the study. Individuals who did not feel susceptible to the hurricane threat may have communicated more messages of efficacy than those who experienced the fear of becoming a victim of a major hurricane. The 
number of blog readers who were most susceptible to the hurricane is unknown; and thus, it can be concluded that blog readers' comments may be skewed according to their vulnerability.

A fourth limitation is the disproportion of blog posts from each source identified by the 2008 Weblog Awards for "Best Science Blog" and the "Top 10 Weather and Climate Blogs" lists. The study included a final sample of fifteen blogs, of which four were local and fifteen were national. This produced an unbalanced number of blog posts (67 posts from national blogs and 34 posts from local blogs. Future studies should attempt to achieve a more equally representative data set.

With regard to the type of blog (national versus local), activity may have varied due to the immediate need for information for its intended target audience. Whereas national blogs mostly serve readers in different geographic areas as well as across a range of weather or science topics, the local blogs in the study deliberately focused on weather and storm information for southeast Texans (as evident by the local blogs appearing on local media websites). Also significant, was the close occurrence of three hurricanes (Hurricanes Gustav, Hanna, and Ike) to threaten the region within weeks. General characteristics of bloggers have been studied (see Rainie, 2005, and Technorati, n.d.); however, blog readers' characteristics are unknown, which may influence their activity.

Notwithstanding, blog posts dated after hurricane landfall were excluded from the current study as the perceived risks associated with hurricane threats/efficacy change once the storm comes ashore. Future research might explore risks associated with hurricanes after landfall, which often include mosquito infestation, displaced livestock, debris hazards, chainsaw accidents, carbon monoxide poisoning from generators, as well as concerns of looting.

Another consideration for future study would be to conduct an experiment in which the EPPM content of messages could be manipulated and included on the blog posts. Such a study could then test for the types of responses to the messages. This might give researchers a better understanding of creating, as well as analyzing EPPM messages. 
Overall, the blogosphere serves a range of audience's needs and communicative functions (i.e. information seeking, persuasion, comfort/support, sense of community, confirmation, and coping) associated with an event (see Wright \& Bell, 2003, Wright, 2000). To this end, perhaps the EPPM content in the present study isn't as dreadful as some may interpret.

This investigation used the EPPM as a way of analyzing messages versus designing messages. Unlike other EPPM studies which might feature a hypothetical threat, this investigation centers on a particular event which poses an imminent physical risk. By focusing on blogs related to Hurricane Ike, the current study responds to recommendations to "gauge Internet usage during disasters" (Piotrowski \& Armstrong, 1998, p. 344). Future investigations of blogs and specific risks, weather-related or otherwise, should apply the EPPM to understand the message components which may be working to achieve behavioral change. Furthermore, these studies should employ methods for measuring actual behaviors to better comprehend the role of blogs in decision-making. 


\section{References}

Aguirre, B.E. (2004). Homeland security warnings: Lessons learned and unlearned. International Journal of Mass Emergencies and Disasters, 22(2), 103-115.

Barnes, M. D., Hanson, C. L., Novilla, L. M. B., Meacham, A. T., McIntyre, E., \& Erickson, B. C. (2008). Analysis of media agenda setting during and after Hurricane Katrina: Implications of emergency preparedness, disaster response, and disaster policy. American Journal of Public Health, 98(4), 604-610.

Bucher, H. J. (2002). Crisis communication and the Internet: Risk and trust in global media. First Monday, 7(4). Retrieved March 3, 2009 from http://www.firstmonday.org/issues/issue7_4/bucher/

Cho, H., \& Witte, K. (2005). Managing fear in public health campaigns: A theory-based formative evaluation process. Health Promotion Practice, 6(4), 482-490.

Choi, Y., \& Lin, Y. H. (2008). A content analysis of the newspaper coverage of the three major hurricanes in 2005. Public Relations Review, 34, 294-296.

Cohen, J. (1960). A coefficient of agreement of nominal scales. Educational and Psychological Measurement, 20(1), 37-46.

Dow, K., \& Cutter, S. L. (2000). Public orders and personal opinions: Household strategies for hurricane risk assessment. Environmental Hazards, 2, 143-155.

Garnett, J. L., Kouzmin, A. (2007). Communicating throughout Katrina: Competing and complementary conceptual lenses on crisis communication. Public Administration Review, 67, 171-188.

Gore, T. D., \& Bracken, C. C. (2005). Testing the theoretical design of a health risk message: Reexamining the major tenets of the extended parallel process model. Health Education \& Behavior, 32(1), 27-41.

Janis, I. L. (1967). Effects of fear arousal on attitude change: Recent developments in theory and experimental research. In L. Berkowitz (Ed.), Advances in experimental and social psychology. (Vol. 3, pp. 166-255). New York: Academic Press.

Kim, J. R. (2004). A theoretical perspective on "fear" as an organizational motivator for initiating public relations activities. Paper presented at the Associated for Education in Journalism in Mass Communication, Toronto.

LaVela, S. L., Smith, B., \& Weaver, F. M. (2007). Perceived risk for influenza in veterans with spinal cord injuries and disorders. Rehabilitation Psychology, 52(4), 458-462. 
Lazo, J. K., Morss, R. E., \& Demuth, J. L. (2009). 300 billion served: Households' sources, perceptions, uses, and values for weather forecast information. Bulletin of the American Meteorological Society.

Lerner, J. S., \& Keltner, D. (2000). Beyond valence: Toward a model of emotion-specific influences on judgment and choice. Cognition and Emotion, 14(4), 473-493.

Leventhal, H. (1970). Findings and theory in the study of fear communications. In L. Berkowitz (Ed.), Advances in experimental and social psychology. (Vol. 5, pp. 119186). New York: Academic Press.

Lindell, M. K., Lu, J. C., \& Prater, C. S. (2005). Household decision making and evacuation in response to Hurricane Lili. National Hazards Review, 6(4), 171-179.

McMahan, S., Witte, K., Meyer, J. (2009). The perception of risk messages regarding electromagnetic fields: Extending the extended parallel processing model to an unknown risk. Health Communication, 10(3), 247-259.

Murray-Johnson, L., Witte, K., Patel, D., Orrego, V., Zuckerman, C., Maxfield, A. M., \& Thimons, E. D. (2004). Using the extended parallel process model to prevent noiseinduced hearing loss among coal miners in Appalachia. Health Education \& Behavior, 31(6), 741-755.

Nelson, D. L. (1979). Remembering pictures and words: Appearance, significance, and name. In L. S. Cermak and F. I. M. Craik (Eds.) Levels of processing in human memory (pp. 45-76). Hillsdale, NJ: Lawrence Erlbaum Associates.

Paivio, A., \& Csapo, K. (1973). Picture superiority in free recall: Imagery or dual coding? Cognitive Psychology, 5, 176-206.

Perry, D. C., Taylor, M., \& Doerfel, M. L. (2003). Internet-based communication in crisis management. Management Communication Quarterly, 17(2), 206-232.

Pfau, M., Haigh, M., Fifrick, A., Holl, D., Tedesco, A., Cope, J., Nunnally, D., Schiess, A., Preston, D., Roszkowski, P., \& Martin, M. (2006). The effects of print news photographs of the casualties of war. Journalism and Mass Communication Quarterly, 83(1), 150-168.

Piotrowski, C., \& Armstrong, T. R. (1998). Mass media preferences in disaster: A study of Hurricane Danny. Social Behavior and Personality, 26(4), 341-346.

Rainie, L. (2005, January 2). The state of blogging. The Pew Internet \& American Life Project. Retrieved March 26, 2009 from http://www.pewinternet.org/Reports/2005/The-State-of-Blogging.aspx 
Riffe, D., Lacy, S., \& Fico, F. G. (1998). Analyzing media messages: Using quantitative content analysis in research. Mahwah, NJ: Lawrence Erlbaum Associates.

Roberto, A. J., Meyer, G., Johnson, A. J., \& Atkin, C. K. (2000). Using the extended parallel process model to prevent firearm injury or death: Field experiment results of a videobased intervention. Journal of Communication, 50(4), 157-175.

Rogers, R. W. (1975). A protection motivation theory of fear appeals and attitude change. Journal of Psychology, 91, 93-114.

Rogers, R. W. (1983). Cognitive and physiological processes in fear arousal upon emotion, attitudes, and cigarette smoking. In J. Cacioppo \& R. Petty (Eds.), Social psychophysiology (pp. 153-176). New York: Guilford.

Roscoe, J. T., \& Byars, J. A. (1971). An investigation of the restraints with respect to sample size commonly imposed on the use of the chi-square statistic. Journal of the American Statistical Association, 66(366), 755-759.

Slovic, P., Fischoff, B., Lichtenstein, S. (1982). Why study risk perception? Risk Analysis, 2(2), 83-93.

Sutton, S. R., \& Hallett, R. (1988). Understanding the effects of fear-arousing communications: The role of cognitive factors and amount of fear aroused. Journal of Behavioral Medicine, 11, 353-360.

Sutton, S. R., \& Hallett, R. (1989). Understanding seat belt intentions and behavior: A decision-making approach. Journal of Applied Social Psychology, 19, 1310-1325.

Sweetser, K. D., \& Metzgar, E. (2007). Communicating during crisis: Use of blogs as a relationship management tool. Public Relations Review, 33, 340-342.

Taylor, M., \& Perry. D. C. (2005). Diffusion of traditional and new media tactics in crisis communication. Public Relations Review, 31, 209-217.

Technorati (n.d.). State of blogosphere 2008. Technorati. Retrieved March 26, 2009 from http://technorati.com/blogging/state-of-the-blogosphere/Thelwall, M., \& Stuart, D. (2007). RUOK? Blogging communication technologies during crises. Journal of Computer-Mediated Communication, 12, 189-214.

Wenger, D., \& Friedman, B. (1986). Local and national media coverage of disaster: A content analysis of the print media's treatment of disaster myths. International Journal of Mass Emergencies and Disasters, 4, 27-50.

Witte, K. (1992). Putting fear back into fear appeals: The extended parallel process model. Communication Monographs, 59, 329-349. 
Witte, K., Meyer, G., \& Martell, D. (2001). Effective health risk messages: A step-by-step guide. Thousand Oaks, CA: Sage Publications.

Witte, K., Peterson, T. R., Vallabhan, S., Stephenson, M. T., Plugge, C. D., Givens, V. K., et al. (1993). Preventing tractor-related injuries and deaths in rural populations: Using a persuasive health message (PHM) framework in formative evaluation research. International Quarterly of Communication Health Education, 13, 219-251.

Wright, A. J., French, D. P., Weinman, J., \& Marteau, T. M. (2006). Can genetic risk information enhance motivation for smoking cessation? An analogue study. Health Psychology, 25(6), 740-752.

Wright, K. B. (2000). Computer-mediated social support, older adults, and coping. Journal of Communication, 50, 100-118.

Wright, K. B., \& Bell, S. B. (2003). Health-related support groups on the Internet: Linking empirical findings to social support and computer-mediated communication theory. Journal of Health Psychology, 8(1), 39-54. 
Appendix A

\section{Extended Parallel Process Model (EPPM)}

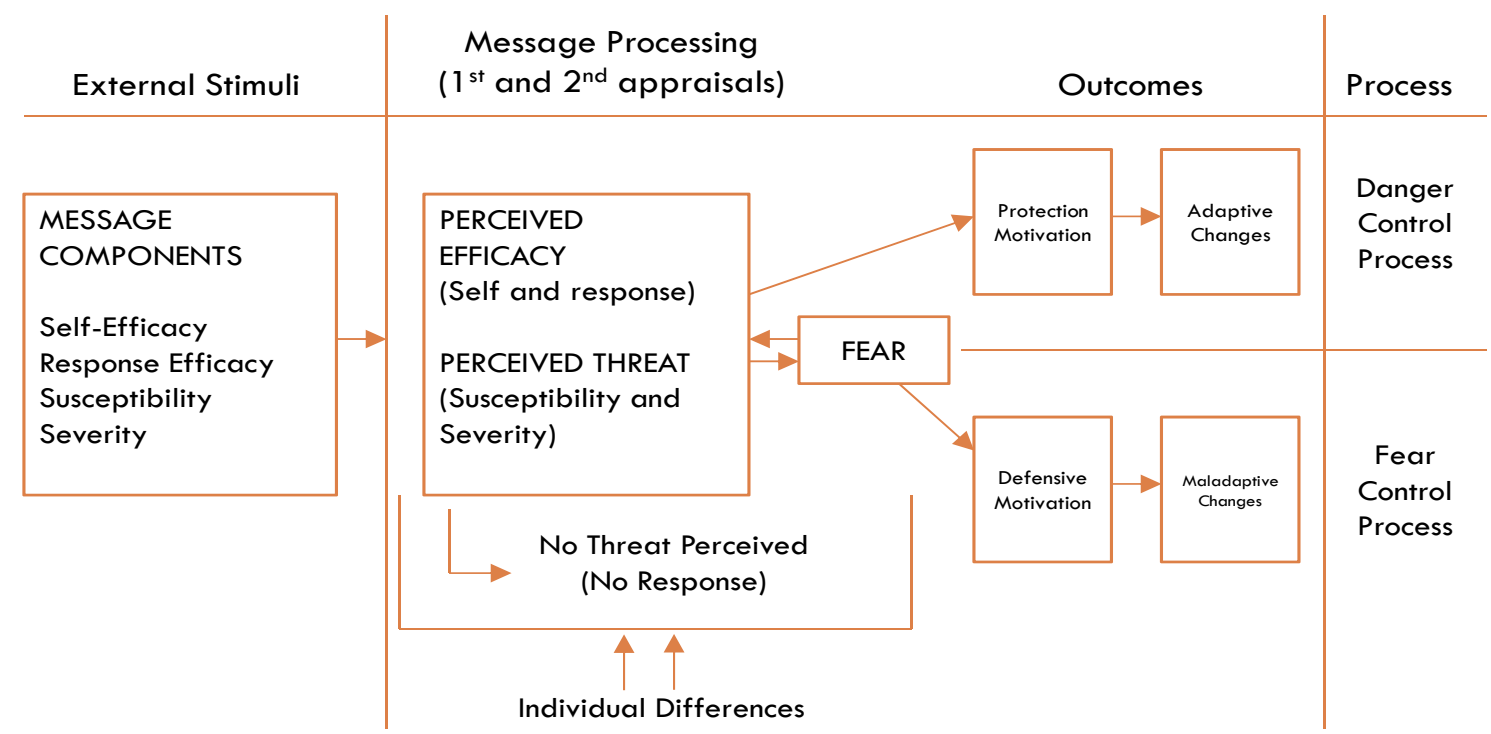




\section{Appendix B}

EPPM Definitions and Examples

\begin{tabular}{|c|c|c|}
\hline Concept & Definition & Example \\
\hline Fear & $\begin{array}{l}\text { Fear is an internal emotional reaction } \\
\text { characterized by subjective experience (the } \\
\text { psychological dimension, e.g. "I am scared") } \\
\text { and the physiological arousal. Fear is aroused } \\
\text { when a serious and personally relevant threat } \\
\text { is perceived. }\end{array}$ & $\begin{array}{l}\text { Fear of heights, spiders, } \\
\text { public speaking, hurricanes }\end{array}$ \\
\hline $\begin{array}{l}\text { Component: } \\
\text { Perceived } \\
\text { Threat }\end{array}$ & $\begin{array}{l}\text { Thoughts or cognitions about a danger or } \\
\text { harm that exists in the environment. } \\
\text { An individual's beliefs about the significance } \\
\text { or magnitude of the threat. }\end{array}$ & $\begin{array}{l}\text { "The storm } \\
\text { strengthening to a category } \\
4 \text { storm." }\end{array}$ \\
\hline Susceptibility & $\begin{array}{l}\text { An individual's beliefs about his/her risk of } \\
\text { experiencing the threat. }\end{array}$ & $\begin{array}{l}\text { "All residents in Galveston } \\
\text { County will be affected." }\end{array}$ \\
\hline $\begin{array}{l}\text { Component: } \\
\text { Perceived } \\
\text { Efficacy }\end{array}$ & $\begin{array}{l}\text { Thoughts or cognitions about the } \\
\text { effectiveness, feasibility, or ease with which a } \\
\text { recommended response prevents a threat. }\end{array}$ & \\
\hline Response & $\begin{array}{l}\text { An individual's beliefs about the effectiveness } \\
\text { of the message's recommendations in } \\
\text { deterring the threat. }\end{array}$ & $\begin{array}{l}\text { "The Mayor is asking all } \\
\text { residents to evacuate the } \\
\text { area." }\end{array}$ \\
\hline Self & $\begin{array}{l}\text { An individual's belief about his/her ability to } \\
\text { carry out a recommended response. }\end{array}$ & $\begin{array}{l}\text { "I won't be able to } \\
\text { evacuate because I don't } \\
\text { have a car." }\end{array}$ \\
\hline
\end{tabular}




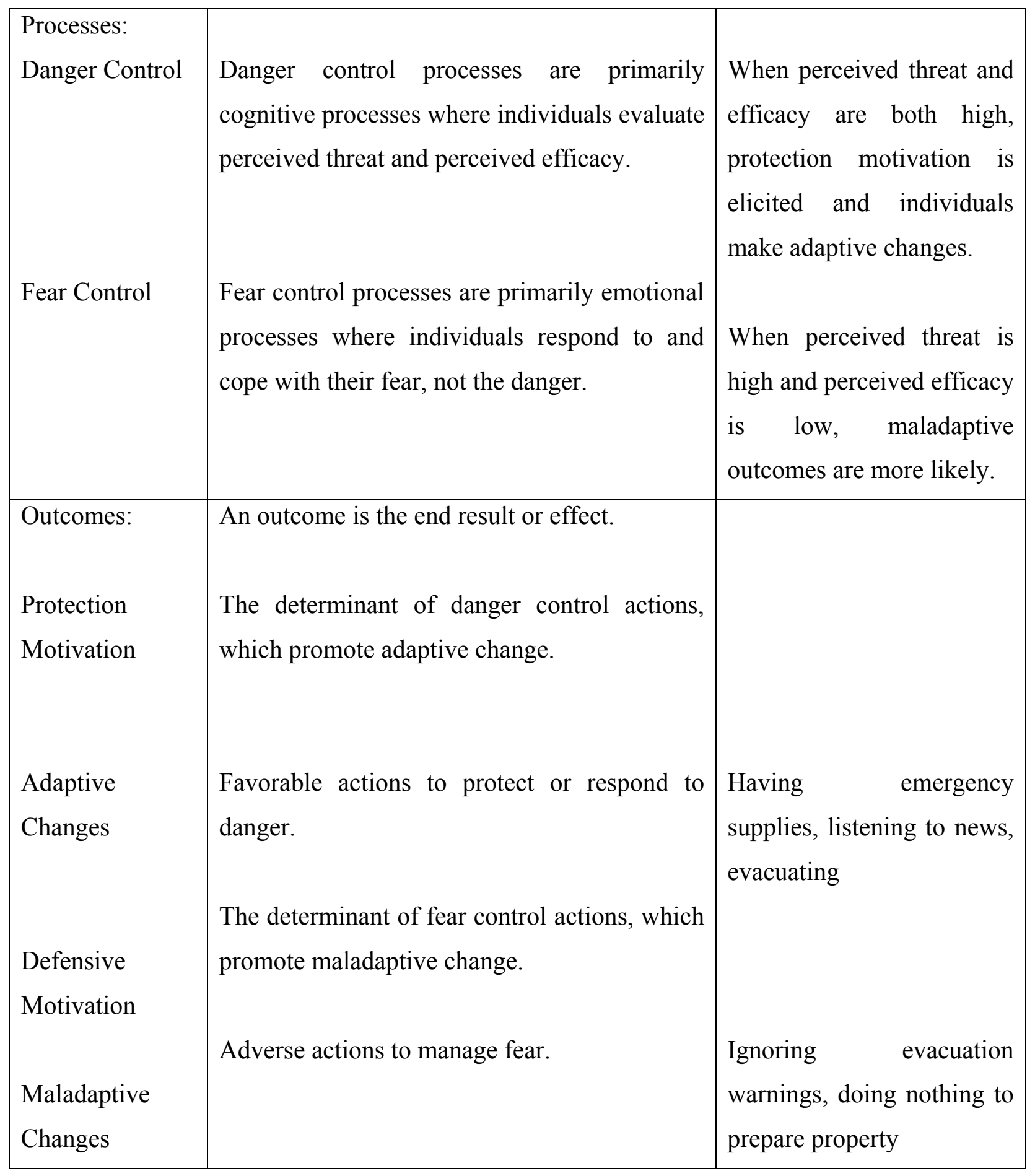

